\title{
Coordinated Regulation of Biosynthetic and Regulatory Genes Coincides with Anthocyanin Accumulation in Developing Eggplant Fruit
}

\author{
John R. Stommel ${ }^{1}$ and Judith M. Dumm \\ U.S. Department of Agriculture, Agriculture Research Service, Beltsville Agricultural Research \\ Center, Genetic Improvement of Fruits and Vegetables Laboratory, Building 010A, BARC-West, \\ 10300 Baltimore Avenue, Beltsville, MD 20705
}

\begin{abstract}
Additional INDEX words. delphinidin, gene regulation, Myb, Myc, Solanum melongena
Abstract. Violet to black pigmentation of eggplant (Solanum melongena L.) fruit is caused by anthocyanin accumulation. Model systems demonstrate the role of regulatory genes in the control of anthocyanin biosynthesis. Anthocyanin structural gene transcription requires the expression of at least one member of each of three transcription factor families: MYB, MYC, and WD. To determine the molecular genetic basis for anthocyanin pigmentation in eggplant fruit, we used real-time polymerase chain reaction (PCR) to evaluate the expression of anthocyanin biosynthetic (Chs, Dfr, Ans) and regulatory $\left(M y c, M y b_{B}, M y b_{C}, W d\right)$ genes in $S$. melongena genotypes that produce fruit with dark violet ('Classic') or white ('Ghostbuster') coloration, respectively. Transcript levels and anthocyanin content were evaluated in fruit at various stages of development ranging from small post-anthesis fruit to full-sized marketable fruit. Anthocyanin content increased 9-fold in developing violet-colored 'Classic' fruit, whereas low but detectable concentrations were found in white 'Ghostbuster' fruit. Chs, Dfr, and Ans as well as $M y b_{C}$ and $M y c$ transcript levels were significantly higher in 'Classic' in comparison with 'Ghostbuster' fruit at comparable stages of fruit development with greatest differences observed for $A n s$ transcript levels. $M y b_{C}$ and $M y c$ transcript levels increased in developing 'Classic' fruit coincident with increasing anthocyanin content. $M y b_{B}$ and $W d$ transcript levels were not coordinated with changes in biosynthetic transcript levels or anthocyanin concentration.
\end{abstract}

Eggplant fruit color is influenced by the presence or absence of anthocyanins and chlorophylls and the concentration as well as distribution of these compounds. Anthocyanins are located in fruit epidermal cells and chlorophylls are found in subepidermal cell layers. Cis- and trans-isomers of the acylated anthocyanin delphinidin-3-p-coumaroylrutinoside-5-glucoside are the predominant anthocyanins commonly reported in eggplant cultivars (Ichiyanagi et al., 2005). Genotypes containing the unacylated delphinidin-3-rutinoside as the major anthocyanin have also been characterized (Sadilova et al., 2006; Tanchev et al., 1970; Wu and Prior, 2005). Dependent on pigment concentrations, the presence of both anthocyanins and chlorophylls results in violet to black fruit color. In the absence of chlorophyll pigments in these developing fruit, varying violet hues occur and are dependent on anthocyanin concentration. Conversely, in the absence of anthocyanin pigments, or if their concentrations are very low, varying fruit chlorophyll concentration results in fruit color ranging from light green to dark green. White fruit color occurs in the absence or very low concentrations of both pigment classes. Concentration of both pigment classes is genotype-dependent and subject to environmental influence. Whereas Western breeders have focused on development of cultivars with dark purple to black- and greencolored fruit, the full range of possible fruit colors are valued in diverse world markets (Daunay et al., 2004).

Anthocyanins are secondary metabolites derived from the phenylpropanoid pathway with important physiological roles in

Received for publication 1 Oct. 2014. Accepted for publication 21 Jan. 2015. Mention of trade names or commercial products is solely for the purpose of providing specific information and does not imply recommendation or endorsement by the U.S. Department of Agriculture.

${ }^{1}$ Corresponding author. E-mail: john.stommel@ars.usda.gov. plant tissues that also influence crop quality and nutritive value. In flowers, anthocyanins may function as attractants for pollinators and aid in the dispersal of seeds and fruit (Harborne, 1994; Schemske and Bradshaw, 1999). They also function in plant tissues as antioxidants and ultraviolet and visible light protectants (Close and Beadle, 2003; Gross, 1991). This class of compounds has generated considerable interest for their presumptive health-promoting effects in mitigating or preventing chronic diseases. Anthocyanins are considered functional dietary components with antiinflammatory and anticarcinogenic activity and have roles in cardiovascular disease prevention, obesity control, and diabetes alleviation properties (He and Giusti, 2010; Pojer et al., 2013).

Anthocyanin biosynthesis has been studied extensively. The enzymes in the anthocyanin biosynthetic pathway are functionally conserved across diverse plant species and the genes that encode these enzymes share high sequence similarity across species. Six enzymes are commonly involved in anthocyanin biosynthesis (Griesbach, 2005). Chalcone synthase (CHS) is the first and key regulatory enzyme of flavonoid biosynthesis. Chalcone is isomerized by chalcone isomerase to naringenin and flavanone 3-hydroxylase converts naringen into dihydrokaempferol. The dihydroflavonols are subsequently converted to a colorless leucoanthocyanidin by dihydroflavonol 4-reductase (DFR), the first committed enzyme of anthocyanin biosynthesis. Leucoanthocyanidins are converted to colored anthocyanidins by anthocyanidin synthase (ANS). UDPglucose-flavonoid 3-O-glucosyltransferase finally produces the anthocyanin-3-glucoside.

Tissue- or developmental-specific anthocyanin biosynthesis is controlled by a MYB-MYC-WD40 regulatory protein complex (Koes et al., 2005). A common set of proteins, comprised 
of 1) MYB proteins characterized by R2 and R3 imperfect repeats of the conserved DNA-binding motif; 2) MYC proteins defined by a conserved basic helix-loop-helix domain consisting of a presumed DNA binding basic region and a proteinprotein dimerization motif; and 3) WD40 repeat proteins with a characteristic 40 residue core containing a glycine-histidine dipeptide at the $\mathrm{N}$-terminus and a tryptophan-aspartate dipeptide at the $\mathrm{C}$-terminus.

Gene families with multiple copies of anthocyanin biosynthetic and regulatory genes have been described within various species (Dooner et al., 1991; Du et al., 2012; Griesbach, 2005; Mol et al., 1996). Evolutionary studies indicate that these multiple copies likely arose from gene duplication followed by sequence divergence (Purugganan and Wessler, 1994). Resulting variation in function of these genes, particularly for regulatory genes, is responsible for differences in pigmentation and patterns of tissue- or developmental-specific pigmentation within and between species. We previously characterized tissue-specific regulation of the anthocyanin biosynthetic pathway in pepper (Capsicum annuum L.), demonstrating differential expression of biosynthetic and regulatory genes coincident with anthocyanin pigmentation in accessions with divergent pigmentation (Stommel et al., 2009). Here, we extend those findings on anthocyanin gene regulation to eggplant, a related Solanaceous species.

\section{Material and Methods}

Plant material and growing conditions. The $S$. melongena hybrid cultivar Classic bears fruit with characteristic purple pigmentation restricted to the fruit peel and the hybrid 'Ghostbuster' bears uniform white-colored fruit. 'Classic' and 'Ghostbuster' were produced from seed and grown at the Beltsville Agricultural Research Center, Beltsville, MD, during the summer (June to September) season under standard greenhouse conditions without supplementary lighting. Six 7-weekold plants of each cultivar were transplanted to $5.7-\mathrm{L}$ pots containing a $65 \%$ to $75 \%$ sphagnum peatmoss plus perlite soilfree mix (Pro-Mix HP Mycorrhizae; Premier Tech Horticulture, Quakertown, PA). Pots were distributed in a glasshouse (lat. $39^{\circ} 1^{\prime} 38.96^{\prime \prime} \mathrm{N}$, long. $\left.76^{\circ} 55^{\prime} 35.67^{\prime \prime} \mathrm{W}\right)$ with climate control (heating started at temperatures below $20{ }^{\circ} \mathrm{C}$ and cooling at temperatures above $24{ }^{\circ} \mathrm{C}$ ) using a completely randomized design. Plants were trained on bamboo canes and spaced $0.8 \mathrm{~m}$ between rows and $0.7 \mathrm{~m}$ apart within the row. Fertilization was applied on a constant feed basis with drip irrigation throughout the growing cycle. Final concentrations of $144 \mathrm{mg} \cdot \mathrm{L}^{-1}$ nitrogen, $42 \mathrm{mg} \cdot \mathrm{L}^{-1}$ phosphorus, $221 \mathrm{mg} \cdot \mathrm{L}^{-1}$ potassium, $106 \mathrm{mg} \cdot \mathrm{L}^{-1}$ calcium, $50 \mathrm{mg} \cdot \mathrm{L}^{-1}$ magnesium, and $34 \mathrm{mg} \cdot \mathrm{L}^{-1}$ sulfur in the dilute fertilizer solution were supplemented with micronutrients applied in final concentrations of $2.8 \mathrm{mg} \cdot \mathrm{L}^{-1}$ iron, 1.3 $\mathrm{mg} \cdot \mathrm{L}^{-1}$ boron, $0.18 \mathrm{mg} \cdot \mathrm{L}^{-1}$ copper, $0.62 \mathrm{mg} \cdot \mathrm{L}^{-1}$ manganese, $0.18 \mathrm{mg} \cdot \mathrm{L}^{-1}$ zinc, $0.09 \mathrm{mg} \cdot \mathrm{L}^{-1}$ molybdenum, and $8.8 \mathrm{mg} \cdot \mathrm{L}^{-1}$ chlorine.

Gene EXPRESSIOn. Fruit peel was sliced from developing fruit, frozen in liquid nitrogen, and stored at $-80{ }^{\circ} \mathrm{C}$. Replicate samples were collected for each of four fruit developmental stages ranging from small fruit enclosed in the calyx (stage w) to glossy full size marketable fruit (stage $\mathrm{z}$ ) (mean fruit weight $\pm \mathrm{SE}$ of stages w, x, y, and $\mathrm{z}$ for 'Classic' and 'Ghostbuster', respectively: $\mathrm{w}=2.7 \pm 0.6 \mathrm{~g}, 1.9 \pm 0.3 \mathrm{~g}$, stage $\mathrm{x}=7.3 \pm 0.9 \mathrm{~g}, 7.7 \pm$ $0.7 \mathrm{~g}$, stage $\mathrm{y}=50.0 \pm 13.5 \mathrm{~g}, 37.7 \pm 0.2 \mathrm{~g}$, stage $\mathrm{z}=645.8 \pm 27.7 \mathrm{~g}$,
$350.8 \pm 19.1 \mathrm{~g})$. Each developmental stage was represented by four replicates obtained from individual fruit of each cultivar. Total RNA for individual samples was isolated from $\approx 1000 \mathrm{mg}$ frozen tissue using the Rneasy Plant Mini Kit with the optional DNase digest (Qiagen, Valencia, CA). RNA quantity was recorded using a spectrophotometer (ND1000; NanoDrop Technologies, Wilmington, DE) and integrity and quantification confirmed using a 2100 Bioanalyzer (Agilent Technologies, Santa Clara, CA).

Real-time PCR was used to compare flavonoid gene expression (Chs, Dfr, Ans, Myb, Myc, Wd) between anthocyaninpigmented and non-pigmented tissues collected from contrasting genotypes. Degenerate primer sets from Petunia $\times$ hybrida Vilm. (Griesbach and Beck, 2005) were used to generate PCR products. PCR products amplified using degenerate primers were cloned and sequenced to identify gene products with homology to published flavonoid gene sequences. The sequences were used to design $S$. melongena gene-specific primers (Table 1). Multiple $M y b$ products with sequence homology to flavonoid related $M y b$ clones from potato (Solanum tuberosum L.) and tomato (Solanum lycopersicum L.) were identified and designated $M y b_{B}$ and $M y b_{C}$, respectively. The sequences of amplified products were used to develop $S$. melongena gene-specific primers (Table 1).

For real time PCR, cDNA synthesis was performed with $1 \mu \mathrm{g}$ RNA using the iScript ${ }^{\mathrm{TM}}$ cDNA Synthesis Kit (Bio-Rad, Hercules, CA). Real-time PCR amplification of the cDNA was carried out as described by Lightbourn et al. (2007) using the iCycler $1 Q^{\mathrm{TM}}$ Multicolor Real-Time Detection System (BioRad). Results were normalized to the expression of $\beta$-tubulin (Tub) where degenerate primers were designed based on gene sequences reported in GenBank (Table 1; Lightbourn et al., 2007). The efficiency of reaction kinetics and $R$ values were tabulated and found to fall within the range of $95 \%$ to $105 \%$ (efficiency) and 0.98 to $1.0(R$ value). Threshold values $[\mathrm{Ct}$ (iQ ${ }^{\mathrm{TM}} 5$ Version 2.0; Bio-Rad)] were manually checked for SD $>$ 0.5 within triplicate reactions. SD of $T u b$ values across fruit development stages and cultivars were $\leq 1.0$. Relative gene expression was normalized to the reference gene as described (Lightbourn et al., 2007).

Flavonoid analysis. Analytical high-performance liquid chromatography (HPLC) (Griesbach et al., 1991) was used to quantify anthocyanin pigments in fruit peel tissue. Sample collection for anthocyanins was equivalent to that described for gene expression studies except duplicate samples were collected for each replicate from each of the four fruit developmental stages. Anthocyanins were extracted in acidified methanol $(1 \% \mathrm{HCl})$, evaporated to dryness, washed with acetone, and re-solubilized in acidified methanol. HPLC characterization of anthocyanidins was performed on a $7.8 \times 300-\mathrm{mm}$ column of 5- $\mu \mathrm{m}$ Bondapak C18 (Waters Corp., Milford, MA) using a $30-\mathrm{min}$ linear gradient of $0 \%$ to $10 \%(\mathrm{v} / \mathrm{v})$ acetonitrile in aqueous $1.5 \%(\mathrm{v} / \mathrm{v})$ phosphoric acid and $15 \%(\mathrm{v} / \mathrm{v})$ acetic acid followed by a $10-\mathrm{min}$ linear increase to $20 \%$ (v/v) acetonitrile and held at $20 \%(\mathrm{v} / \mathrm{v})$ acetonitrile for an additional $20 \mathrm{~min}$. Flow rate was $1.0 \mathrm{~mL} \cdot \mathrm{min}^{-1}$ and detection was by absorption at 540 $\mathrm{nm}$. Anthocyanins were identified as previously described (Lightbourn et al., 2008). Anthocyanin content was determined by measuring sample peak areas obtained from replicate samples of each cultivar using Maxima software (Waters Corp.). The relative amount of pigment was calculated as the mean of the area of absorption per gram fresh weight. 
Table 1. Solanum melongena gene-specific primers for real-time polymerase chain reaction amplification of flavonoid biosynthetic and regulatory genes.

\begin{tabular}{|c|c|c|}
\hline Gene symbolz $^{z}$ & & Primer sequence $\left(5^{\prime}-3^{\prime}\right)$ \\
\hline \multirow[t]{2}{*}{ Chs } & Forward & TTG CCT AGC ATC AAG AGA AGG AGC \\
\hline & Reverse & AGG AGG AAT TCA AGC GCA TGT GTG \\
\hline \multirow[t]{2}{*}{$D f r$} & Forward & ATC TTC TTA GCA TAT ATG AAG TCC AAG TCG \\
\hline & Reverse & TCC AAG GAC CCT GAG AAT GAA G \\
\hline \multirow[t]{2}{*}{ Ans } & Forward & TTG TGG TCA ACT TGA GTG GGA GGA \\
\hline & Reverse & TAT GAG CTT CGA CGC CAA GTG CTA \\
\hline \multirow[t]{2}{*}{$M y b_{B}$} & Forward & TTA CTG CTT CTT TTC СТT CTC CTC G \\
\hline & Reverse & TCC TTC AAA CGA CGA TGT TAT TTC T \\
\hline \multirow{2}{*}{$M y b_{C}$} & Forward & ACA TGC AAA GAC ATC ATT AGT ACG \\
\hline & Reverse & ТCT ТCT ТCT СCT TCA ACA GCG TCG \\
\hline \multirow[t]{2}{*}{ Myc } & Forward & GCA GCC AAT AGA AGT TAC TGC TGA AG \\
\hline & Reverse & ACC ATT CGG ATT CCG TCA AGT CCT \\
\hline \multirow[t]{2}{*}{$W d$} & Forward & ATT GGA ATG AGG TGG AGC CCA GAA \\
\hline & Reverse & CCC ATC AGC AGA AAC GGA AGC AAA \\
\hline \multirow[t]{2}{*}{ Tub } & Forward & TGG CTA CCA TCA AGA CTA AGC GCA \\
\hline & Reverse & AGA CCT CAG CAA CAC TGG TTG AGT \\
\hline
\end{tabular}

$\overline{{ }^{z} C h s}=$ chalcone synthase; $D f r=$ dihydroflavonol reductase; $A n s=$ anthocyanidin synthase; $T u b=$ tubulin.

\section{Results}

The $S$. melongena cultivars Classic and Ghostbuster produce characteristically dark violet and white-colored fruit, respectively (Fig. 1). Delphinidin-3- $p$-coumaroylrutinoside-5-glucoside was identified as the major anthocyanin present in fruit peels of 'Classic' and 'Ghostbuster'. Anthocyanin concentration increased 9-fold during early fruit development (stages w, x, y) in 'Classic' and subsequently declined 5-fold in full-sized market quality fruit [stage z (Table 2)]. Very low but detectable anthocyanin concentrations were found in 'Ghostbuster'. Anthocyanin concentration in fruit peels of this white-pigmented genotype did not change significantly during fruit development and were $\approx 145$ - to 1000 -fold lower relative to those found in 'Classic' at comparable stages of fruit development.

The presence of measureable anthocyanin concentration in epidermal tissues of violet as well as white-colored fruit of these two genotypes indicated that functional anthocyanin biosynthetic pathways were present. The expression of regulatory genes $\left(M y c, M y b_{B}, M y b_{C}, W d\right)$ that comprise the MYBMYC-WD transcription factor complex and key biosynthetic genes ( $C h s, D f r, A n s$ ) were evaluated to characterize the genetic mechanism underlying differences observed in fruit pigmentation of these cultivars.

With the exception of $C h s$ transcript level in stage $\mathrm{z}$ fruit of 'Classic' and 'Ghostbuster', significant differences between 'Classic' and 'Ghostbuster' Chs, Dfr, and Ans transcript occurred at all stages of fruit development. Chs and $D f r$ transcript levels were $\approx 750$ - and 5700 -fold greater, respectively, in 'Classic' vs. 'Ghostbuster' in stage y fruit, coincident with peak measures of anthocyanin concentration (Table 3). The greatest fold difference in structural gene expression was for Ans, where transcript levels were 353,000-fold greater in stage y fruit of 'Classic' in comparison with 'Ghostbuster'. In violet-pigmented epidermal tissue of 'Classic' fruit, transcript levels for all three genes increased between stage w through stage y coincident with increases in anthocyanin concentration. 'Classic' Chs and Dfr transcript levels increased 4-fold, and Ans transcript increased 6-fold in small developing fruit between stage $\mathrm{w}$ and stage $\mathrm{y}$. Biosynthetic transcript levels for 'Classic' decreased 4.5- to 14-fold between stage y and stage $\mathrm{z}$, coincident with declines in anthocyanin concentration of fullsized fruit. Similar to anthocyanin concentration in developing 'Ghostbuster' fruit, transcript levels for all three biosynthetic genes were relatively unchanged throughout fruit development.

$M y b$ products with sequence homology to flavonoid-related $M y b$ clones from potato and tomato were identified in developing eggplant fruit and designated $M y b_{B}$ and $M y b_{C}$, respectively. $M y b_{B}$ transcript levels were up to 10 -fold greater in developing fruit of 'Classic' vs. 'Ghostbuster' but exhibited little or no change throughout fruit development in either cultivar and were present at low levels relative to those for $M y b_{C}$ (Table 4). Significant differences between 'Classic' and 'Ghostbuster' transcript levels were found at all stages of fruit development. $M y b_{C}$ and $M y c$ transcript levels were up to 14.5and 288-fold greater in 'Classic' vs. 'Ghostbuster' fruit at comparable stages of fruit development. $M y b_{C}$ transcript level in 'Classic' fruit increased 2.6-fold between stage $\mathrm{w}$ and stage $\mathrm{y}$, and $M y c$ transcript increased over 7.7-fold in developing fruit coincident with increasing biosynthetic transcript level and anthocyanin concentration. Transcript for both regulatory genes subsequently declined in market-sized fruit (stage z) coincident with declines in biosynthetic transcript level and anthocyanin concentration. Little or no change in $M y b_{C}$ or $M y c$ was observed in 'Ghostbuster'. $W d$ transcript increased $\approx 2$-fold in 'Classic' between stage $\mathrm{w}$ and stage $\mathrm{y}$ as biosynthetic transcript level and anthocyanin concentration increased. However, transcript levels in 'Classic' vs. 'Ghostbuster' were not significantly different at comparable stages of fruit development. $W d$ transcript level was relatively unchanged during fruit development in 'Ghostbuster' and increased in market-sized fruit of both cultivars relative to smaller stage y fruit.

\section{Discussion}

Despite the importance of eggplant worldwide as a food crop and considerable interest in eggplant fruit secondary metabolites for their nutritive value, little research has been conducted to understand the molecular mechanisms that control anthocyanin accumulation in this crop. Early genetic studies describing 


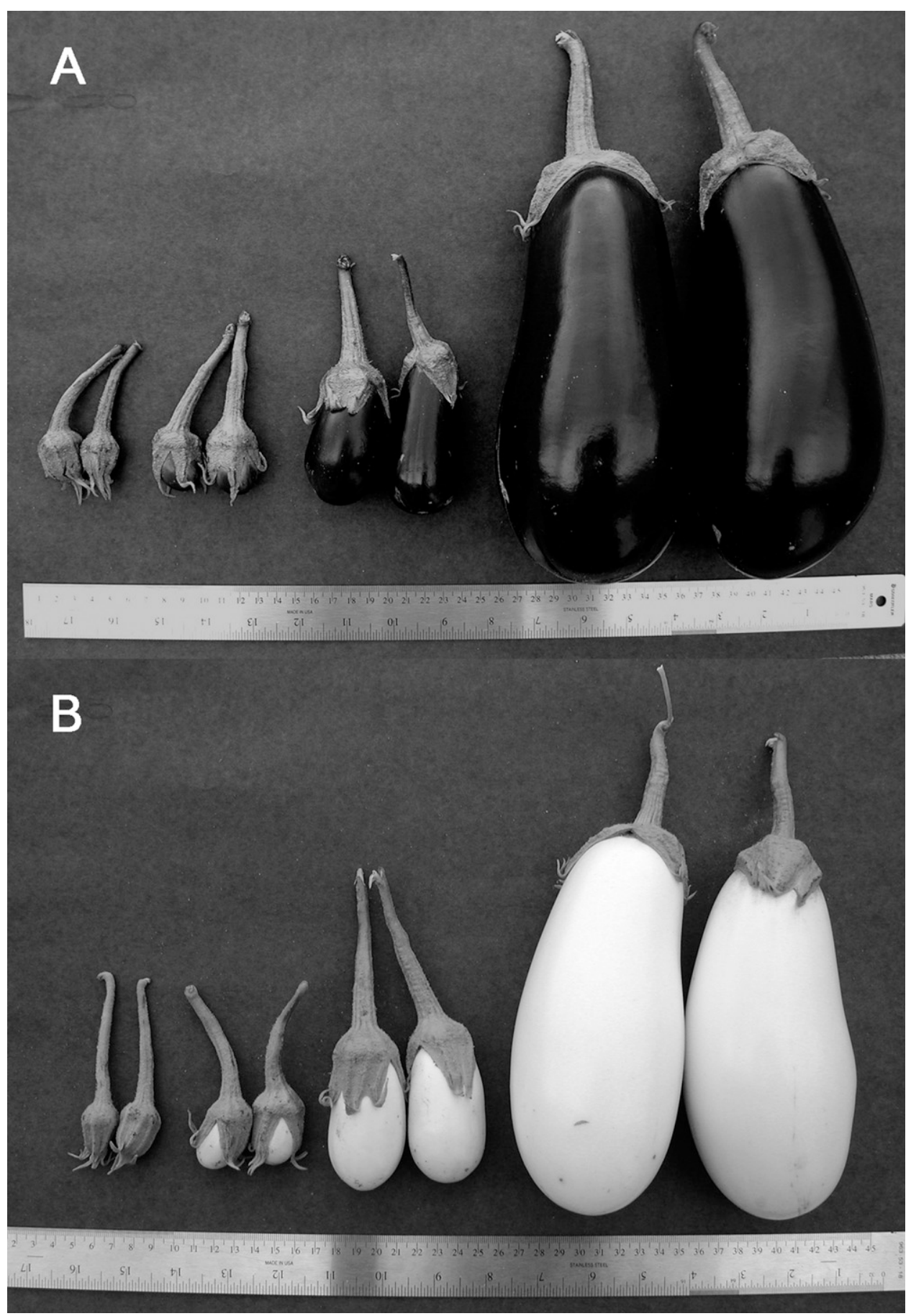

Fig. 1. Solanum melongena anthocyanin pigmented 'Classic' (A) and non-pigmented 'Ghostbuster' (B) fruit sampled for anthocyanin content and gene expression at varying stages of fruit development ranging from small fruit fully enclosed in the calyx (stage $\mathrm{w}$ ), intermediate size developing fruit (stages $\mathrm{x}$ and $\mathrm{y}$ ), to glossy full-sized marketable fruit (stage $\mathrm{z}$ ). Mean fruit weight of stages w, $\mathrm{x}, \mathrm{y}$, and $\mathrm{z}$ for 'Classic' and 'Ghostbuster', respectively: stage $\mathrm{w}=2.7$ and $1.9 \mathrm{~g}, \mathrm{x}=7.3$ and $7.7 \mathrm{~g}, \mathrm{y}=50.0$ and $37.7 \mathrm{~g}, \mathrm{z}=645.8$ and $350.8 \mathrm{~g}$.

the inheritance of eggplant fruit pigmentation (Tigchelaar et al., 1968 ) and more recent anthocyanin pigmentation-linked quantitative trait loci studies (Barchi et al., 2012; Cericola et al., 2014) support the action of multiple genetic factors that influence anthocyanin pigmentation. Using a genome-wide association mapping approach, Cericola et al. (2014) identified 56 single nucleotide polymorphism (SNP) markers associated with anthocyanin pigmentation. Ten of these SNP loci, scattered over five chromosomes, were associated with fruit color. Synteny between eggplant and other Solanaceous species enabled speculation on possible orthologs associated with fruit color. Eggplant fruit color-associated markers identified on chromosome 10 were syntenic with chromosomal regions in tomato and potato harboring anthocyaninrelated genes, namely, UDP-glucose:flavonoid-3- $O$-glucosyltransferase (3GT) and two MYB transcription factors that regulate the genes encoding CHS and DFR and influence tissue specific anthocyanin expression (Cericola et al., 2014).

We report differential expression of Chs, Dfr, and Ans biosynthetic genes in eggplant fruit with violet vs. white fruit color as a result of high vs. very low anthocyanin concentration, respectively. All three biosynthetic genes were highly expressed in violet fruit relative to white fruit. Upregulation of both $M y b_{C}$ and $M y c$ regulatory genes, coincident with increased expression of anthocyanin biosynthetic genes and anthocyanin concentration in developing fruit post-anthesis through market maturity stages of development, suggest that differential expression of $M y b_{C}$ and $M y c$ are important determinants of anthocyanin accumulation in these genotypes. Whereas $M y b_{C}$ with sequence homology to a tomato $M y b$ clone was differentially expressed in eggplant fruit, $M y b_{B}$ with sequence homology to a potato $M y b$ clone did not exhibit differential expression and was expressed at very low levels relative to $M y b_{C}$. Zhang et al. (2014) recently reported upregulation of anthocyanin biosynthetic genes and $M y b$ in violet anthocyaninpigmented eggplant fruit 12 to $15 \mathrm{~d}$ post-anthesis. The investigators did not observe differential expression of $M y c$. Anthocyanin pigmentation of small developing fruit enclosed in the calyx suggests that 'Classic' carries the dominant Puc (Pigment under calyx) allele (Tigchelaar et al., 1968) and that anthocyanin synthesis in this cultivar is not light-dependent.

Our focus on Chs, Dfr, and Ans biosynthetic genes does not preclude differential regulation of other anthocyanin biosynthetic genes as determinants of observed fruit pigmentation. However, differential $M y b_{C}$ and $M y c$ expression in violet- vs. white-colored fruit suggests that regulation of anthocyanin 
biosynthesis and resulting fruit color in these genotypes is associated with expression of these transcription factors. In well-studied plant systems including Arabidopsis thaliana (L.) Heynh., Zea mays L., P. ×hybrida, and Vitis vinifera L. (Du et al., 2012; Dubos et al., 2010; Feller et al., 2011; FournierLevel et al., 2010; Griesbach, 2005; Matus et al., 2008),

Table 2. Anthocyanin content in fruit peel of anthocyanin-pigmented ('Classic') and non-pigmented ('Ghostbuster') eggplant fruit. ${ }^{\text {' }}$

\begin{tabular}{|c|c|c|}
\hline \multirow[b]{3}{*}{ Stage $^{y}$} & \multicolumn{2}{|c|}{ Genotype } \\
\hline & Classic & Ghostbuster \\
\hline & \multicolumn{2}{|c|}{$\begin{array}{l}\text { Anthocyanin content }[(\text { peak area/ } \\
\left.\text { gram fresh wt tissue }) \times 10^{4}\right] \\
\end{array}$} \\
\hline $\mathrm{W}$ & $1,642.7 \mathrm{a}^{\mathrm{x}}$ & $19.6 \mathrm{a}$ \\
\hline $\mathrm{x}$ & $4,153.9 \mathrm{~b}$ & $5.3 \mathrm{a}$ \\
\hline $\mathrm{y}$ & $15,148.0 \mathrm{c}$ & $15.4 \mathrm{a}$ \\
\hline $\mathrm{z}$ & $2,955.7 \mathrm{~b}$ & $20.3 \mathrm{a}$ \\
\hline
\end{tabular}

${ }^{\mathrm{z}}$ Duplicate samples were collected from each of four fruit for each of four fruit developmental stages ranging from small fruit fully enclosed in the calyx (stage w), intermediate-sized developing fruit (stages $\mathrm{x}$ and $y$ ), to glossy full-sized marketable fruit (stage $z$ ).

${ }^{\mathrm{y}}$ Mean fruit weight of stages $\mathrm{w}, \mathrm{x}, \mathrm{y}$, and $\mathrm{z}$ for 'Classic' and 'Ghostbuster', respectively: stage $\mathrm{w}=2.7$ and $1.9 \mathrm{~g}, \mathrm{x}=7.3$ and $7.7 \mathrm{~g}$, $\mathrm{y}=50.0$ and $37.7 \mathrm{~g}, \mathrm{z}=645.8$ and $350.8 \mathrm{~g}$.

'Letters denote Fisher's least significant difference multiple comparison test $(P \leq 0.001)$ conducted within a cultivar; means followed by the same letter are not significantly different. multiple MYB encoding genes have been reported. In $A$. thaliana, 13 or more MYBs are related to the regulation of flavonoid metabolism and control specific anthocyanin biosynthetic enzymes and/or tissue specificity and may be redundant with other members of the MYB gene family (Dubos et al., 2010). Similarly, in grape, numerous anthocyanin MYBs were identified. However, only two MYBs located on chromosome 2 differentiated presence vs. absence of anthocyaninpigmented fruit color (Fournier-Level et al., 2010; Matus et al., 2008). More recently, a candidate gene association study of grape accessions with a diverse range of fruit color identified fruit anthocyanin-associated transcription factors that included a MYC encoded on chromosome 2 and two MYBs, one identified on chromosome 9 and a second of unknown location (Cardoso et al., 2012). Similarly, discrete regulation of fruit anthocyanin content by one or several anthocyanin MYBs and MYCs has been reported for other Solanaceous species including pepper (Stommel et al., 2009) and tomato (Gonzali et al., 2009) and roseaceous fruits including apple (Malus domestica Borkh.) and pear (Pyrus communis L.) (Jaakola, 2013). Our results demonstrating differential regulation of MYB and MYC coincident with fruit anthocyanin pigmentation are congruent with these results. Functional studies are needed to confirm the biological roles of these eggplant transcription factors.

The role of the MYC-MYB-WD40 regulatory protein complex is well accepted for its role in anthocyanin biosynthesis

Table 3. Relative expression for eggplant anthocyanin structural genes in anthocyanin-pigmented ('Classic') and non-pigmented ('Ghostbuster') fruit peels. ${ }^{\mathrm{z}}$

\begin{tabular}{|c|c|c|c|c|c|c|}
\hline \multirow[b]{3}{*}{ Stage $^{y}$} & \multicolumn{6}{|c|}{ Gene $^{x}$} \\
\hline & \multicolumn{2}{|c|}{ Chs } & \multicolumn{2}{|c|}{$D f r$} & \multicolumn{2}{|c|}{ Ans } \\
\hline & \multicolumn{6}{|c|}{ Relative expression (mean $\pm \mathrm{SE}$ ) } \\
\hline $\mathrm{x}$ & $0.87 \pm 0.36$ & $0.003 \pm 0.002$ & $2.97 \pm 0.47$ & $0.001 \pm 2 \times 10^{-4}$ & $1.02 \pm 0.26$ & $4 \times 10^{-5} \pm 2 \times 10^{-5}$ \\
\hline $\mathrm{y}$ & $2.27 \pm 0.38$ & $0.003 \pm 0.002$ & $5.73 \pm 0.71$ & $0.001 \pm 1 \times 10^{-4}$ & $3.18 \pm 0.51$ & $9 \times 10^{-6} \pm 2 \times 10^{-6}$ \\
\hline $\mathrm{z}$ & $0.16 \pm 0.06$ & $0.002 \pm 1 \times 10^{-4}$ & $1.26 \pm 0.30$ & $0.002 \pm 5 \times 10^{-4}$ & $0.69 \pm 0.18$ & $6 \times 10^{-6} \pm 2 \times 10^{-6}$ \\
\hline
\end{tabular}

${ }^{\mathrm{z} F o u r ~ b i o l o g i c a l ~ r e p l i c a t e s ~ o b t a i n e d ~ f r o m ~ i n d i v i d u a l ~ f r u i t ~ o f ~ e a c h ~ c u l t i v a r ~ w e r e ~ c o l l e c t e d ~ f o r ~ e a c h ~ o f ~ f o u r ~ f r u i t ~ d e v e l o p m e n t a l ~ s t a g e s ~ r a n g i n g ~ f r o m ~}$ small fruit fully enclosed in the calyx (stage w), intermediate-sized developing fruit (stages x and y), to glossy full-sized marketable fruit (stage z). Expression values are normalized to tubulin.

${ }^{\mathrm{y}}$ Mean fruit weight of stages w, $\mathrm{x}, \mathrm{y}$, and $\mathrm{z}$ for 'Classic' and 'Ghostbuster', respectively: stage $\mathrm{w}=2.7 \mathrm{and} 1.9 \mathrm{~g}, \mathrm{x}=7.3 \mathrm{and} 7.7 \mathrm{~g}, \mathrm{y}=50.0$ and $37.7 \mathrm{~g}, \mathrm{z}=645.8$ and $350.8 \mathrm{~g}$.

${ }^{\mathrm{x}} \mathrm{Chs}=$ chalcone synthase; $D f r=$ dihydroflavonol reductase; $A n s=$ anthocyanidin synthase.

Table 4. Relative expression for eggplant anthocyanin regulatory genes in anthocyanin-pigmented ('Classic') and non-pigmented ('Ghostbuster') fruit peels. ${ }^{\mathrm{z}}$

\begin{tabular}{|c|c|c|c|c|c|c|c|c|}
\hline \multirow[b]{4}{*}{ Stage $^{y}$} & \multicolumn{8}{|c|}{ Gene } \\
\hline & \multicolumn{2}{|c|}{$M y b_{B}$} & \multicolumn{2}{|c|}{$M y b_{C}$} & \multicolumn{2}{|r|}{ Myc } & \multicolumn{2}{|c|}{ Wd } \\
\hline & Classic & Ghostbuster & Classic & Ghostbuster & Classic & Ghostbuster & Classic & Ghostbuster \\
\hline & \multicolumn{8}{|c|}{ Relative expression (mean $\pm \mathrm{SE})$} \\
\hline $\mathrm{x}$ & $2 \times 10^{-4} \pm 2 \times 10^{-4}$ & $4 \times 10^{-4} \pm 2 \times 10^{-4}$ & $0.05 \pm 0.01$ & $0.02 \pm 0.004$ & $0.39 \pm 0.08$ & $0.005 \pm 0.001$ & $0.87 \pm 0.26$ & $0.69 \pm 0.17$ \\
\hline $\mathrm{y}$ & $1 \times 10^{-4} \pm 8 \times 10^{-5}$ & $8 \times 10^{-4} \pm 2 \times 10^{-4}$ & $0.21 \pm 0.03$ & $0.02 \pm 0.004$ & $1.15 \pm 0.07$ & $0.004 \pm 0.001$ & $0.86 \pm 0.14$ & $0.85 \pm 0.16$ \\
\hline $\mathrm{z}$ & $2 \times 10^{-5} \pm 8 \times 10^{-6}$ & $1.8 \times 10^{-5} \pm 9 \times 10^{-6}$ & $0.03 \pm 0.01$ & $0.002 \pm 4 \times 10^{-4}$ & $0.83 \pm 0.24$ & $0.003 \pm 3 \times 10^{-4}$ & $2.99 \pm 0.85$ & $2.02 \pm 0.17$ \\
\hline
\end{tabular}

${ }^{\mathrm{z}}$ Four biological replicates obtained from individual fruit of each cultivar were collected for each of four fruit developmental stages ranging from small fruit fully enclosed in the calyx (stage w), intermediate-sized developing fruit (stages x and y), to glossy full-sized marketable fruit (stage z). Expression values are normalized to tubulin.

${ }^{\mathrm{y}}$ Mean fruit weight of stages w, $\mathrm{x}, \mathrm{y}$, and $\mathrm{z}$ for 'Classic' and 'Ghostbuster', respectively: stage $\mathrm{w}=2.7 \mathrm{and} 1.9 \mathrm{~g}, \mathrm{x}=7.3 \mathrm{and} 7.7 \mathrm{~g}, \mathrm{y}=50.0 \mathrm{and}$ $37.7 \mathrm{~g}, \mathrm{z}=645.8$ and $350.8 \mathrm{~g}$. 
(Koes et al., 2005). Numerous investigations have demonstrated that all three transcription factors are required for anthocyanin production. $M y b$ and $M y c$ provide one of the best examples of combinatorial plant gene regulation. Together with the WD40 protein, MYB and MYC provide extensive regulatory function in plants and result in new phenotypic traits by virtue of variation in the MYC or, more commonly, the MYB component (Ramsay and Glover, 2005). Z. mays $M y b_{C 1}$ and $M y c_{L c}$ are two of the alleles that are well studied. They have been expressed in a number of plant species (Bovy et al., 2002; Bradley et al., 1998; Goldsbrough et al., 1996; Lloyd et al., 1992; Quattrocchio et al., 1993) in which they either enhanced the amount of anthocyanin produced or activated biosynthesis in unpigmented tissues. We reported differential regulation of both $M y b$ and $M y c$ in pepper genotypes with dichotomous anthocyanin pigmentation (Stommel et al., 2009). Ma et al. (2008) reported that $M y b$ as well as $M y c$ expression were required to elicit high levels of anthocyanin accumulation in Phalaenopsis amabilis (L.) Blume flowers. In P. ×hybrida, the combination $M y c_{A n 1} / M y b_{A n 2}$ induces anthocyanin pigmentation in the flower; MycAn1/MybAn4 induces anthocyanin pigmentation in the anthers; whereas the $M y c_{A n 1} / M y b_{P h 4}$ combination induces vacuolar acidification (Quattrocchio et al., 2006). Neither regulatory gene alone was sufficient to influence anthocyanin content. Differences in the threshold requirements for these regulatory genes to activate anthocyanin production also differ in different plants. In mammalian cells, both the MYC protein and mRNA have relatively short halflives (Sharova et al., 2009). As a result, its temporal level and functionality in transcription factor complexes is dependent on transcription rate or promoter strength.

Numerous studies have documented the role of plant MYB proteins in conferring tissue- and cell-specific anthocyanin regulation and their influence on regulatory control of multiple aspects of epidermal cell differentiation (Koes et al., 2005; Quattrocchio et al., 2006). Relative to MYB proteins, plant MYC proteins have been studied less extensively. This class of transcription factors was first identified in Z. mays where they determine the timing, amount, and distribution of anthocyanin pigmentation (Ludwig et al., 1989). The N-terminal region of plant $M y c$ bHLH transcription factors has an $\approx 190$ amino acid $\mathrm{N}$-terminus that defines the MYB-interacting region. After this interaction domain is an activation domain that is responsible for transactivation of biosynthetic gene promoters in the anthocyanin pathway. Pattanaik et al. (2006) demonstrated that a lysine to methionine substitution in the interaction domain of MYC-RP of Perilla frutescens (L.) Britt. resulted in a 50-fold increase in transactivation activity. Ectopic expression of MYC-RP in transgenic tobacco (Nicotiana tabacum L.) resulted in increased anthocyanin accumulation relative to expression of the wild-type gene. Pattanaik et al. (2006) also documented MYC variants from Antirrhinum majus L. that showed increased transactivation of the A. thaliana Chs promoter. Changes in the interaction domain likely influence anthocyanin biosynthesis through 1) increased transactivation strength of respective MYC variants; 2) increased transactivation strength and improved interaction of MYC variants with MYB proteins; or 3) more stable bHLH-MYB-WD complexes resulting in enhanced anthocyanin production (Pattanaik et al., 2008).

In the current study, $W d$ expression was constitutive in both violet anthocyanin-pigmented eggplant fruit and white fruit with very low anthocyanin concentration. $W d$ transcript levels were comparable in both genotypes and were not differentially regulated coincident with anthocyanin accumulation. Similarly, differential $W d$ expression was not observed in $P$. amabilis (Ma et al., 2009) or pepper (Stommel et al., 2009). Despite lack of differential regulation, the essential role of WD40 proteins in the transcription factor complex is highlighted in recent studies (Aguilar-Barragan and Ochoa-Alejo, 2014) where silencing of $W d$ resulted in significant reduction of anthocyanin biosynthetic genes. All of these observations are consistent with the proposed model for the MYC-MYB-WD40 regulatory protein complex where WD40 serves as a platform for interaction with MYCs that in turn interact with MYBs (Koes et al., 2005). MYB and MYC appear to be sufficient in providing specificity in the regulatory complex, which binds to structural gene promoters to initiate gene expression.

Available studies document diversity in anthocyanin-related MYB, MYC, and WD40 transcription factors. DNA as well as protein binding sites of MYB, MYC, and WD40 proteins impose differential constraints on variability that can be tolerated in these proteins so that structure and functionality can be maintained (Ramsay and Glover, 2005; Streisfeld et al., 2011). Nonetheless, sufficient variation exists among one or multiple components of the transcription factor complex to produce varied anthocyanin composition and concentration and tissue and temporal specificity observed for anthocyanin biosynthesis. Our results on coordinated regulation of anthocyanin biosynthetic and regulatory genes in $S$. melongena further illustrate diversity within and among these transcription factors in Solanaceous species and more distant genera.

\section{Literature Cited}

Aguilar-Barragan, A. and N. Ochoa-Alejo. 2014. Virus-induced silencing of MYB and WD40 transcription factor genes affects the accumulation of anthocyanin in chili pepper fruit. Biol. Plant. 58:567-574.

Barchi, L., S. Lanteri, E. Portis, G. Valè, A. Volante, L. Pulcini, T. Ciriaci, N. Acciarri, V. Barbierato, L. Toppino, and G.L. Rotino. 2012. A RAD tag derived marker based eggplant linkage map and the location of QTLs determining anthocyanin pigmentation. PLoS One 7:e43740.

Bovy, A., R. de Vos, M. Kemper, E. Schijlen, M. Almenar Pertejo, S. Muir, G. Collins, S. Robinson, M. Verhoeyen, S. Hughes, C. Santos-Buelga, and A. van Tunen. 2002. High-flavonol tomatoes resulting from the heterologous expression of the maize transcription factor genes $L C$ and C1. Plant Cell 14:2509-2526.

Bradley, J.M., K.M. Davies, S.C. Deroles, S.J. Bloor, and D.H. Lewis. 1998. The maize $L c$ regulatory gene up regulates the flavonoid biosynthetic pathway of petunia. Plant J. 13:381-392.

Cardoso, S., W. Lau, J.E. Dias, P. Fevereiro, and N. Maniatis. 2012. A candidate-gene association study for berry color and anthocyanin content in Vitis vinifera L. PLoS One 7:E4602.

Cericola, F., E. Portis, S. Lanteri, L. Toppino, L. Barchi, N. Acciarri, L. Pulcini, T. Sala, and G.L. Rotino. 2014. Linkage disequilibrium and genome-wide association analysis for anthocyanin pigmentation and fruit color in eggplant. BMC Genomics 15:896.

Close, D.C. and C.L. Beadle. 2003. The ecophysiology of foliar anthocyanin. Bot. Rev. 69:149-161.

Daunay, M.C., S. Aubert, A. Frary, S. Doganlar, R.N. Lester, G. Barendse, G. van der Weerden, J.W. Hennart, J. Haanstra, F. Dauphin, and E. Jullian. 2004. Eggplant (Solanum melongena) fruit colour: Pigments, measurements and genetics. Proc. XIIth EUCARPIA Mtg. Genetics and Breeding of Capsicum and Eggplant, Noordwijkerhout, The Netherlands, 17-19 May 2004. p. 108-116. 
Dooner, H.K., T.P. Robbins, and R.A. Jorgensen. 1991. Genetic and developmental control of anthocyanin biosynthesis. Annu. Rev. Genet. 25:173-199.

Du, H., B.R. Feng, S.S. Yang, Y.B. Huang, and Y.X. Tang. 2012. The R2R3-MYB transcription factor gene family in maize. PLoS One 7:e37463.

Dubos, C., R. Stracke, E. Grotewold, B. Weisshaar, C. Martin, and L. Lepiniec. 2010. MYB transcription factors in Arabidopsis. Trends Plant Sci. 15:573-581.

Feller, A., K. Machemer, E.L. Braun, and E. Grotewold. 2011. Evolutionary and comparative analysis of MYB and bHLH plant transcription factors. Plant J. 66:94-116.

Fournier-Level, A., T. Lacombe, L. Le Cunff, J.M. Boursiquot, and P. This. 2010. Evolution of the $V v M y b A$ gene family, the major determinant of berry colour in cultivated grapevine (Vitis vinifera L.). Heredity 104:351-362.

Goldsbrough, A.P., Y. Tong, and J.I. Yoder. 1996. $L c$ as a nondestructive visual reporter and transposition excision marker gene for tomato. Plant J. 9:927-933.

Gonzali, S., A. Mazzucato, and P. Perata. 2009. Purple as a tomato: Towards high anthocyanin tomatoes. Trends Plant Sci. 14:237-241. Griesbach, R.J. 2005. Biochemistry and genetics of flower color. Plant Breed. Rev. 25:89-114.

Griesbach, R.J., S. Asen, and B.A. Leonhardt. 1991. Petunia hybrida anthocyanins acylated with caffeic acid. Phytochemistry 30:1729-1731.

Griesbach, R.J. and R.M. Beck. 2005. Sequence analysis of the chalcone synthase gene in four Petunia taxa. J. Amer. Soc. Hort. Sci. 130:360-365.

Gross, J. 1991. Pigments in vegetables: Chlorophylls and carotenoids. AVI, New York, NY.

Harborne, J.B. 1994. The flavonoids: Advances in research since 1986. Chapman and Hall, London, UK.

He, J.A. and M.M. Giusti. 2010. Anthocyanins: Natural colorants with health-promoting properties. Annu. Rev. Food Sci. Technol. 1:163-187. Ichiyanagi, T., Y. Kashiwada, Y. Shida, Y. Ikeshiro, T. Kaneyuki, and T. Konishi. 2005. Nasunin from eggplant consists of cis-trans isomers of delphinidin 3-[4-(p-coumaroyl)-L-rhamnosyl (1-6)glucopyranoside]5-glucopyranoside. J. Agr. Food Chem. 53:9472-9477.

Jaakola, L. 2013. New insights into the regulation of anthocyanin biosynthesis in fruits. Trends Plant Sci. 18:477-483.

Koes, R., W. Verweij, and F. Quattrocchio. 2005. Flavonoids: A colorful model for the regulation and evolution of biochemical pathways. Trends Plant Sci. 10:236-242.

Lightbourn, G.J., R.J. Griesbach, J.A. Novotny, B.A. Clevidence, D.D. Rao, and J.R. Stommel. 2008. Effects of anthocyanin and carotenoid combinations on foliage and immature fruit color of Capsicum annuum L. J. Hered. 99:105-111.

Lightbourn, G.J., J.R. Stommel, and R.J. Griesbach. 2007. Epistatic interactions influencing anthocyanin gene expression in Capsicum annuum. J. Amer. Soc. Hort. Sci. 132:824-829.

Lloyd, A.M., V. Walbot, and R.W. Davis. 1992. Arabidopsis and Nicotiana anthocyanin production activated by maize regulators $R$ and $C 1$. Science 258:1773-1775.

Ludwig, S.R., L.F. Habera, S.L. Dellaporta, and S.R. Wessler. 1989. $L c$, a member of the maize $R$ gene family responsible for tissue specific anthocyanin production, encodes a protein similar to transcriptional activators and contains the myc-homology region. Proc. Natl. Acad. Sci. USA 86:7092-7096.

Ma, H., M. Pooler, and R. Griesbach. 2008. Ratio of $M y c$ and $M y b$ transcription factors regulates anthocyanin production in orchid flowers. J. Amer. Soc. Hort. Sci. 133:133-138.

Ma, H., M. Pooler, and R. Griesbach. 2009. Anthocyanin regulatory/ structural gene expression in Phalaenopsis Blume. J. Amer. Soc. Hort. Sci. 134:88-96.
Matus, J.T., F. Aquea, and P. Arce-Johnson. 2008. Analysis of the grape $M Y B R 2 R 3$ subfamily reveals expanded wine quality-related clades and conserved gene structure organization across Vitis and Arabidopsis genomes. BMC Plant Biol. 8:83.

Mol, J., G. Jenkins, E. Schafer, and D. Weiss. 1996. Signal perception, transduction, and gene expression involved in anthocyanin biosynthesis. Crit. Rev. Plant Sci. 15:525-557.

Pattanaik, S., C.H. Xie, Q. Kong, K.A. Shen, and L. Yuan. 2006. Directed evolution of plant basic helix-loop-helix transcription factors for the improvement of transactivational properties. Biochim. Biophys. Acta 1759:308-318.

Pattanaik, S., C.H. Xie, and L. Yuan. 2008. The interaction domains of the plant Myc-like bHLH transcription factors can regulate the transactivation strength. Planta 227:707-715.

Pojer, E., F. Mattivi, D. Johnson, and C.S. Stockley. 2013. The case for anthocyanin consumption to promote human health: A review. Comprehensive Rev. Food Sci. Food Safety 12:483-508.

Purugganan, M.D. and S.R. Wessler. 1994. Molecular evolution of the plant $R$ regulatory gene family. Genetics 138:849-854.

Quattrocchio, F., W. Verweij, A. Kroon, C. Spelt, J. Mol, and R. Koes. 2006. PH4 of Petunia is an R2R3MYB protein that activates vacuolar acidification through interactions with basic-helix-loop-helix transcription factors of the anthocyanin pathway. Plant Cell 18:12741291.

Quattrocchio, F., J.F. Wing, H.T.C. Leppen, J.N.M. Mol, and R.E. Koes. 1993. Regulatory genes controlling anthocyanin pigmentation are functionally conserved among plant species and have distinct sets of target genes. Plant Cell 5:1497-1512.

Ramsay, N.A. and B.J. Glover. 2005. MYB-bHLH-WD40 protein complex and the evolution of cellular diversity. Trends Plant Sci. 10:63-70.

Sadilova, E., F.C. Stintzing, and R. Carle. 2006. Anthocyanins, colour and antioxidant properties of eggplant (Solanum melongena L.) and violet pepper (Capsicum annuum L.) peel extracts. Z. Naturforsch. C 61:527-535.

Schemske, D.W. and H.D. Bradshaw. 1999. Pollinator preference and the evolution of floral traits in monkeyflowers (Mimulus). Proc. Natl. Acad. Sci. USA 96:11910-11915.

Sharova, L.V., A.A. Sharov, T. Nedorezov, Y. Piao, N. Shaik, and M.S.H. Ko. 2009. Database for mRNA half-life of 19977 genes obtained by DNA microarray analysis of pluripotent and differentiating mouse embryonic stem cells. DNA Res. 16:45-58.

Stommel, J.R., G.J. Lightbourn, B.S. Winkel, and R.J. Griesbach. 2009. Transcription factor families regulate the anthocyanin biosynthetic pathway in Capsicum annuum. J. Amer. Soc. Hort. Sci. 134:244-251

Streisfeld, M.A., D. Liu, and M.D. Rausher. 2011. Predictable patterns of constraint among anthocyanin-regulating transcription factors in Ipomoea. New Phytol. 191:264-274.

Tanchev, S.S., P.J. Ruskov, and C.F. Timberlake. 1970. The anthocyanins of Bulgarian aubergine (Solanum melongena). Phytochemistry 9:1681-1682.

Tigchelaar, E.C., J. Janick, and H.T. Erickson. 1968. The genetics of anthocyanin coloration in eggplant (Solanum melongena L.). Genetics 60:475-491.

$\mathrm{Wu}, \mathrm{X}$. and R.L. Prior. 2005. Identification and characterization of anthocyanins by high-performance liquid chromatographyelectrospray ionization-tandem mass spectrometry in common foods in the United States: Vegetables, nuts and grains. J. Agr. Food Chem. 53:3101-3113.

Zhang, Y., Z. Hu, G. Chu, C. Huang, S. Tian, Z. Zhao, and G. Chen. 2014. Anthocyanin accumulation and molecular analysis of anthocyanin biosynthesis-associated genes in eggplant (Solanum melongena L.). J. Agr. Food Chem. 62:2906-2912. 